Article

\title{
Increasing Summer Rainfall and Asymmetrical Diurnal and Seasonal Warming Enhanced Vegetation Greenness in Temperate Deciduous Forests and Grasslands of Northern China
}

\author{
Mei Yu * and Qiong Gao \\ Department of Environmental Sciences, University of Puerto Rico-Rio Piedras, San Juan, PR 00936, USA; \\ q.gao@ites.upr.edu \\ * Correspondence: meiyu@ites.upr.edu
}

Received: 12 June 2020; Accepted: 7 August 2020; Published: 10 August 2020

check for updates

\begin{abstract}
Temperate forests and grasslands carry key ecosystem functions and provide essential services. Remote-sensing derived greenness has been widely used to assess the response of ecosystem function to climate and land-cover changes. Although reforestation and grassland restoration have been proposed to enhance the regional greenness in Northern China, the independent contribution of climate without the interference of land-cover change at meso and large scales has rarely been explored. To separate the impacts of climate change on vegetation greenness from those of land-cover/use change, we identified large patches of forests and grasslands in Northern China without land-cover/use changes in 2001-2015 and derived their greenness using MODIS enhanced vegetation index (EVI). We found that most deciduous-broadleaved forest patches showed greening, and the significant slope of the annual mean and maximum EVI are $3.97 \pm 0.062 \times 10^{-3}$ and $4.8 \pm 0.116 \times 10^{-3} \mathrm{yr}^{-1}$, respectively. On the contrary, grassland patches showed great spatial heterogeneity and only those in the east showed greening. The partial correlation analysis between EVI and climate showed that the greening of grassland patches is primarily supported by the increased growing-season precipitation with mean significant coefficient of $0.72 \pm 0.01$. While wet-year $(0.57 \pm 0.01)$ and nongrowing-season precipitation $(0.68 \pm 0.01)$ significantly benefit greening of deciduous-broadleaved forests, the altered temperature seasonality modulates their greening spatial-heterogeneously. The increased growing-season minimum temperature might lengthen the growing season and contribute to the greening for the temperature-limited north as shown by positive partial correlation coefficient of $0.66 \pm 0.01$, but might elevate respiration and reduce greening of the forests in the south as shown by negative coefficient of $-0.70 \pm 0.01$. Daytime warming in growing season is found to favor the drought-tolerant oak dominated forest in the south due to enhanced photosynthesis, but may not favor the forests dominated by less-drought-tolerant birch in the north due to potential water stress. Therefore, grassland greening was essentially promoted by the growing-season precipitation, however, in addition to being driven by precipitation, greening of deciduous forests was regulated spatial-heterogeneously by asymmetrical diurnal and seasonal warming which could be attributed to species composition.
\end{abstract}

Keywords: temperate grasslands; deciduous broadleaved forests; vegetation greening; asymmetrical warming

\section{Introduction}

The derivation of remotely-sensed vegetation indices is based on absorbance of red light and reflectance of near infrared light by chlorophylls mostly lying in plant leaves [1]. Vegetation indices 
have been widely used as efficient tools to monitor spatiotemporally and consistently the dynamics of living leaf biomass, leaf area index, land surface phenology, and ecosystem structures and functions such as carbon sequestration from local to global scales [2-5]. As an important recent finding using vegetation indices, about one-third of the global vegetated land has been getting greener since 2000, and China and India are leading the greening mostly due to land-use management such as afforestation and intensified agriculture [6].

The dynamics of vegetation greenness have been reported to be driven by climate change, land-use/cover change, elevated atmospheric $\mathrm{CO}_{2}$ concentration, and altered soil nutrients such as those through nitrogen deposition [2,7]. Climate affects vegetation greenness by regulating water availability, carbon assimilation, partition of assimilated products to leaf, and onset and ending of growing season. In the long-term, vegetation greenness is also affected by climate-induced land-cover changes such as woody plant encroachment to grassland.

Temperate deciduous forests and grasslands feature the strongest seasonality of greenness with strong climate modulation than other vegetation types. Temperate forests and grasslands occupy 10.4 and $15.0 \times 10^{6} \mathrm{~km}^{2}$ land, respectively, represent $19 \%$ of global ice-free land, share an essential portion of global ecosystem functions, and provide important ecosystem services, such as timber and forage [8]. The net primary production of temperate forests and grasslands is 7.6 and $5.3 \mathrm{Pg} \mathrm{C} \mathrm{yr}^{-1}$, respectively, accounting for $22 \%$ of the global ecosystems.

As the amount of leaf area of vegetation is mostly determined by available soil moisture [8], the dynamics of greenness of temperate forests and grasslands should be primarily controlled by the balance of moisture input to and output from the ecosystems. Ample soil moisture promotes primary production and allometric leaf growth of temperate forests and grasslands by enhancing the plant physiological activities and the soil nutrient availability [9-12]. Thus, effective precipitation is important in driving vegetation greenness of temperate forests and grasslands. In addition, rainfall during summer/autumn tends to delay autumn dormancy in temperate deciduous forests and to extend the growing season, and winter and spring precipitation allows the well-developed root systems of woody vegetation to hold enough soil moisture for plant early leaf-out in spring, thus to enhance the greenness of temperate vegetation [13-15].

Temperature is also crucial for green leaf production of temperate vegetation and regulates the physiological activities of plant and soil microbes [10,16]. Compared to rainfall effects on greenness, temperature is more determinative for the length of growing season [14,17]. Additionally, moisture output from an ecosystem via evapotranspiration is sensitive to temperature [18]. Global warming and its diurnal and seasonal patterns affect photosynthesis and respiration differently [19-21]. Nighttime warming is much stronger than daytime warming [22] and the asymmetric warming greatly affects vegetation leaf growth and vegetation greenness. Furthermore, nighttime warming in early spring or late autumn reduced the chances of frost damage and/or accelerated the thermal-time accumulation for leaf-out, and therefore advanced the start but delayed the end of growing season, both of which render longer growing seasons [23-25].

Modeling of vegetation greenness with various statistical and data science approaches aims to answer the question of how climate and other biophysical variables interact to determine the spatiotemporal dynamics of vegetation greenness and related ecosystem functions. Vegetation indices were often used as dependent variable and climate as independent variable to explore the dependence of vegetation greenness on climate change [7]. Most of such studies have a common implicit assumption of negligible effects of land-cover change. While the assumption might be justified for areas with slow and insignificant land-cover changes, it is not valid for areas with fast and extensive land-cover changes driven by the profound economic growth [6]. For areas with fast land-cover changes, ignoring the land-cover changes will bias the equation derived for greenness and related ecosystem parameters such as phenology $[4,7,26]$.

To address the climate effects on vegetation greenness while insulating the impacts of land-cover/use changes on greenness, we carefully chose large patches of the temperate forest 
and grassland without land-cover/use changes in Northern China ranging from wet temperate to dry temperate zones, and investigated the changes in greenness of these patches, the changes in climate and its seasonality, and responses of greenness dynamics to changes in climate. Forest and grassland in Northern China have different mechanisms in their responses to climate changes because of the diverse root-to-shoot ratio, the species composition, and the phenology and longevity among others $[9,11,27,28]$. An amplified wetting trend in northern high-latitude region was highlighted due to the enhancement of poleward atmospheric moisture transport [29]. We hypothesize the following: temperate forests and grasslands exhibit divergent greenness responses to changing climate; compared to well-developed root systems of forests, the shallow-root grasslands are more sensitive to enhanced summer precipitation [30]; greenness of temperate forests and grasslands responds divergently to asymmetric warming diurnally and seasonally $[19,31,32]$; and species composition further differentiates the direction and/or magnitude of forest greenness [12].

\section{Materials and Methods}

\subsection{Climate and Vegetation Index for Deciduous-Broadleaved Forests and Grasslands}

We obtained meteorological data of 674 stations (Figure 1) with total precipitation, $P(\mathrm{~mm})$, maximum $\left(T_{\max }\right)$ and minimum $\left(T_{\min }\right)$ temperatures $\left({ }^{\circ} \mathrm{C}\right)$ in the period of $2000-2015$ from the China Meteorological Administration [7]. The daily data were averaged for temperatures or summed for precipitation for each month and each wet year (from 1 October of previous year to 30 September of current year, or called water year) [33]. We then interpolated the monthly precipitation using kriging and the monthly maximum and minimum temperatures using cokriging with elevation as covariate at the spatial resolution of $1 \mathrm{~km}$ (ArcGIS 10, ESRI, Redlands, CA, USA).

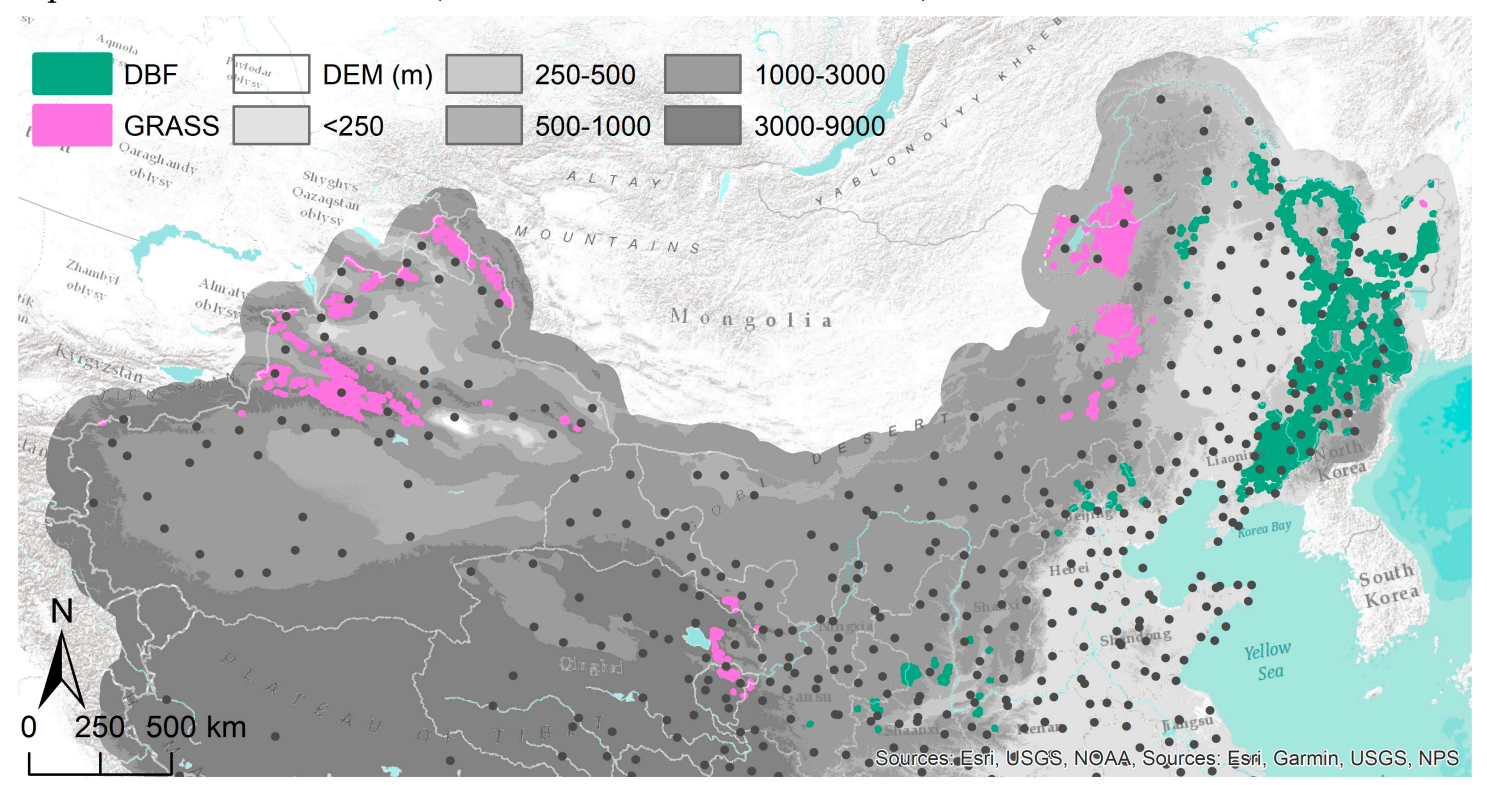

Figure 1. Locations of temperate deciduous-broadleaved forest (DBF) and grassland (GRASS) patches selected in Northern China. Dots indicate weather stations.

Large patches of deciduous-broadleaved forest and grassland without land-cover change were identified based on the annual land-cover maps of 2001-2015 for China, classified from MODIS imagery with the virtual ground-truth interpreted from high-resolution Google Earth images [34-36], with an area larger than $21 \mathrm{~km}^{2}$. An inward buffer zone of $900 \mathrm{~m}$ was applied to minimize edge effect. In total, we identified 569 patches of deciduous-broadleaved forest (average size of $119 \pm 10 \mathrm{~km}^{2}$ ) and 311 grassland patches (average size of $117 \pm 14 \mathrm{~km}^{2}$ ). For each patch, we extracted time series of MODIS enhanced vegetation index (EVI, product MOD13Q1 V006) following the quality control 
recommendation from the data provider [37] and averaged for the patch by means of Google Earth Engine [38]. This Level 3 product provides EVI and pixel quality assurance (QA) generated for every 16 days at $250 \mathrm{~m}$. The vegetation indices are computed from the atmospherically corrected surface reflectance and masked for clouds and their shadows, water, and heavy aerosols, and the best available value during the 16-day period is used for low clouds and view angle but high EVI value [37].

\subsection{Trend Analysis and Partial Correlation between EVI and Climate}

We calculated annual and maximum EVI $\left(\mathrm{EVI}_{a}\right.$ and $\left.\mathrm{EVI}_{m}\right)$ for each patch during May-September for each year as this period is considered as typical growing season in Northern China. Then, we derived the temporal trends in $\mathrm{EVI}_{a}$ and $\mathrm{EVI}_{m}$ based on the time series regression with the first order of autocorrelation using $\mathrm{R}$ nlme package [39]. Trend of the greenness is quantified with the regression slope describing the rate of change. Wet-year climate was also extracted for each patch and precipitation, $P$, annual mean maximum and minimum temperature, $T_{\max }$ and $\underline{T}_{\min }$, were computed for each wet-year, each growing season (May-September), and each nongrowing season (prior October-April). The temporal trends of these climate variables were then derived using the time series analysis abovementioned.

To explore the EVI responses to climate, we calculated the partial correlations between the EVI and the climate variables (annual, growing-season, and nongrowing-season precipitation, maximum and minimum temperatures) using the R ppcor package [40]. The advantage to use partial correlation is to eliminate the effects of other covariables when partial correlation coefficient is computed between two variables. Specifically, when calculating the partial correlations of EVI with annual precipitation, we set the annual minimum and maximum temperatures as covariables. When calculating the partial correlations between EVI and growing-season precipitation, we set the growing-season $T_{\min }$ and $T_{\max }$ and the nongrowing-season $P, T_{\min }$, and $T_{\max }$, as covariables. The covariables for the partial correlation of EVI with nongrowing-season precipitation are the nongrowing-season $T_{\min }$ and $T_{\max }$ and the growing-season $P, T_{\min }$, and $T_{\max }$. Similar settings are applied to the partial correlations with $T_{\min }$ and $T_{\max }$.

\section{Results}

\subsection{EVI Trends}

Deciduous-broadleaved forest patches (DBF, Figures 2 and 3) showed mostly positive trends for both $\mathrm{EVI}_{a}$ (563 out of 569 total patches) and $\mathrm{EVI}_{m}$ (544 patches) with $3.5 \pm 0.065 \times 10^{-3}$ and $3.4 \pm 0.096 \times 10^{-3} \mathrm{yr}^{-1}$ as slopes, respectively. For those patches with the slopes significantly greater than 0 or significantly lower than 0 at $p<0.05$ (one-tail test), the average slopes are $3.97 \pm 0.062 \times 10^{-3}$ and $4.8 \pm 0.116 \times 10^{-3} \mathrm{yr}^{-1}$ for $\mathrm{EVI}_{a}$ (461 patches) and $\mathrm{EVI}_{m}$ (298 patches), respectively. Grassland patches showed great spatial heterogeneity in EVI trends (GRASS, Figures 2 and 3), that is, increasing trends of both $\mathrm{EVI}_{a}$ and $\mathrm{EVI}_{m}$ in the east, but decreasing in the west. There are 220 patches (out of 311 total patches) showing a positive trend in $\mathrm{EVI}_{a}$ and 192 patches showing positive trend in $\mathrm{EVI}_{m}$. As to the significant trends of $\mathrm{EVI}_{a}$, the averages are $4.2 \pm 0.13 \times 10^{-3}$ and $-4.8 \pm 0.29 \times 10^{-3} \mathrm{yr}^{-1}$ for positive significant trends (102 patches, significantly greater than 0 at $p<0.05)$ in the east and negative significant trends (39 patches, significantly lower than 0 at $p<0.05$ ) in the west, respectively. The histograms of significant slopes detected as greater than 0 or lower than 0 at $p<0.025$ (one-tail test) are shown in Appendix A Figure A1 for reference. 

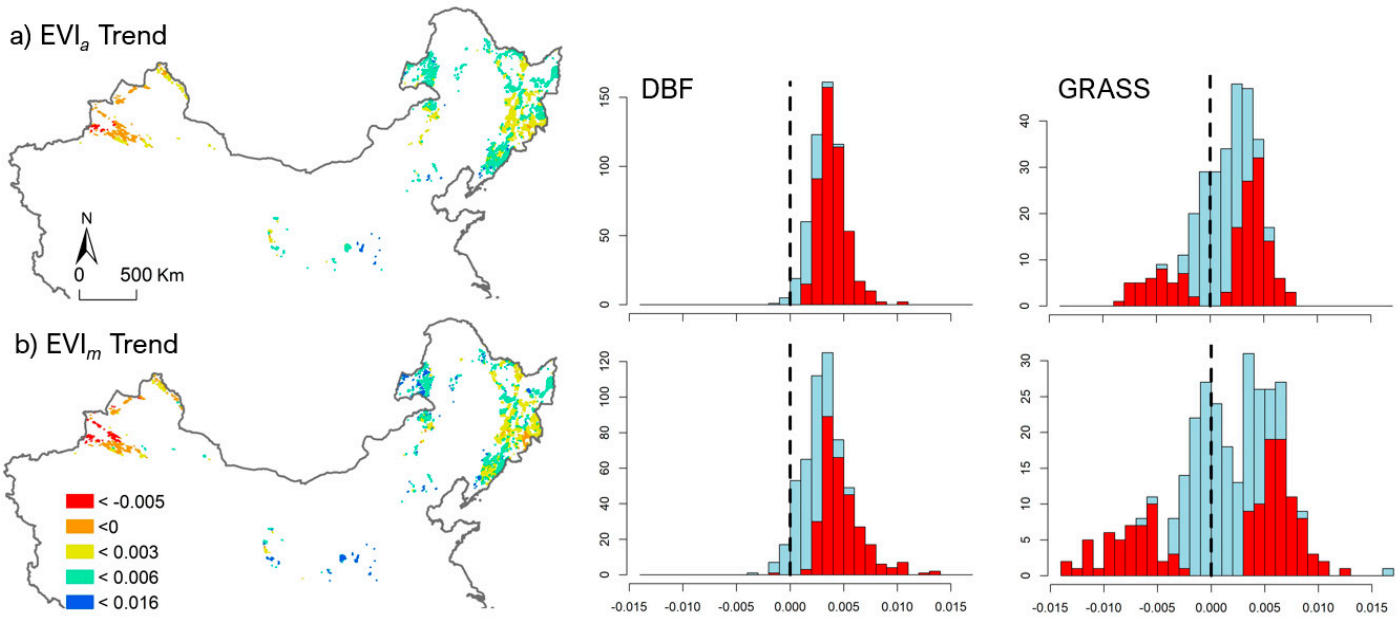

Figure 2. Trends of averaged (a) and maximum (b) enhanced vegetation index (EVI) $\left(\mathrm{yr}^{-1}\right)$ during growing season, May-September, in 2001-2015 for grassland (GRASS) and deciduous-broadleaved forest (DBF) patches. $\mathrm{EVI}_{a}$ and $\mathrm{EVI}_{m}$ indicate averaged and maximum EVI during growing season, respectively; right columns are histograms in blue (all trends) and red (significant trends) bars, and red bars on the left side of the dashed line indicate those trends significantly lower than 0 while those on the right side of the dashed line indicate the trends significantly greater than 0 ( $p$-value $<0.05$, one-tail test).
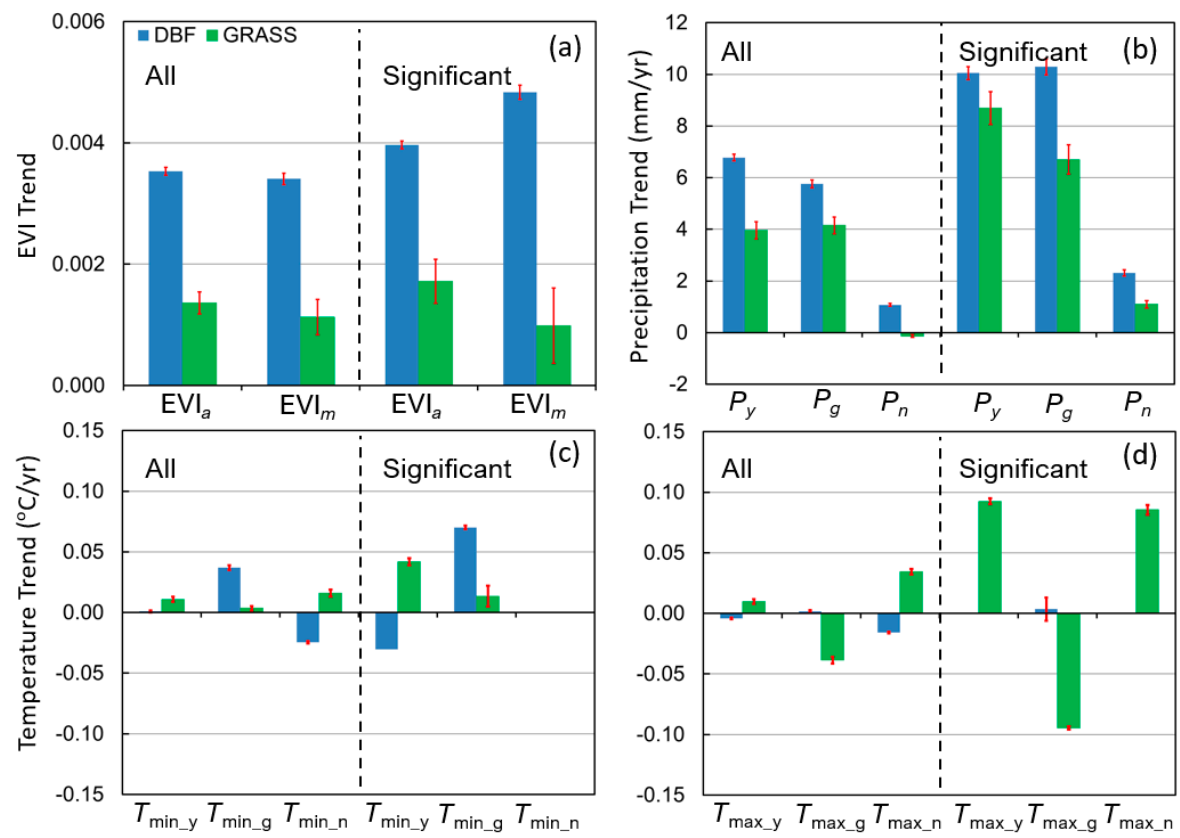

Figure 3. Average and stand error of slopes of mean and maximum EVI during May-September (a), and slopes of climate variables in wet-year (prior October to this September), growing-season, and nongrowing-season precipitation (b), minimum temperature (c), and maximum temperature (d) in 2001-2015 for grassland (GRASS) and deciduous-broadleaved forest (DBF) patches. $\mathrm{EVI}_{a}$ and $\mathrm{EVI}_{m}$ indicate averaged and maximum EVI during growing season, respectively; $P, T_{\min }, T_{\max }$ indicate precipitation, minimum, and maximum temperatures, respectively; and $\mathrm{y}, \mathrm{g}$, and $\mathrm{n}$ indicate wet-year, growing-season, and nongrowing-season, respectively. Summary of all trends is displayed on the left side of the dashed line and summary over the significant trends, i.e., significantly lower than 0 or significantly greater than 0 ( $p$-value $<0.05$, one-tail test), is shown on the right side of the dashed lines. 


\subsection{Climate Trends}

Precipitation showed mostly increasing trends for both deciduous-broadleaved forests and grasslands patches (Figure 4a). For deciduous-broadleaved forests, wet-year, growing-season, and nongrowing-season precipitation increased at the rates of $6.78 \pm 0.13,5.76 \pm 0.15$, and $1.08 \pm 0.05 \mathrm{~mm} \mathrm{yr}^{-1}$, respectively. For those forest patches with positive significant slopes, i.e., slopes significantly greater than 0 at $p<0.05$ (one-tail test), these rates are $10.05 \pm 0.25(n=115)$, $10.29 \pm 0.31(\mathrm{n}=120)$, and $2.57 \pm 0.05(\mathrm{n}=82) \mathrm{mm} \mathrm{yr}^{-1}$, respectively. On the other hand, the slopes of precipitation of the grassland patches during wet year, growing season, and nongrowing season are $3.96 \pm 0.34,4.15 \pm 0.32$, and $-0.13 \pm 0.05 \mathrm{~mm} \mathrm{yr}^{-1}$, respectively. However, the negative precipitation trends are found mostly distributed in the west within desert steppe whereas positive trends were mostly found in the east, a pattern similar to the spatial distribution of EVI trends (Figures 2 and 4a). The mean and standard error of the positive significant precipitation slopes, that is, significantly greater than 0 at $p<0.05$, are $11.73 \pm 0.17(\mathrm{n}=82), 11.38 \pm 0.22(\mathrm{n}=95)$, and $1.55 \pm 0.05(\mathrm{n}=49) \mathrm{mm} \mathrm{yr}^{-1}$, respectively for wet year, growing season, and nongrowing season.

The trends of temperature also showed sharp comparison between the forests and the grasslands. Minimum temperature increased during growing season but decreased during nongrowing season for the deciduous-broadleaved forest patches in the east (Figure $4 \mathrm{~b}$ ). The slopes in wet-year, growing-season, and nongrowing-season $T_{\min }$ are $0.001 \pm 0.001,0.037 \pm 0.002$, and $-0.025 \pm 0.001{ }^{\circ} \mathrm{C} \mathrm{yr}^{-1}$, respectively. For those patches with positive slopes significantly greater than 0 at $p<0.05, T_{\min }$ increased in growing season at $0.07 \pm 0.001{ }^{\circ} \mathrm{C} \mathrm{yr}^{-1}(\mathrm{n}=330)$. In contrast to the trend of $T_{\min }$ for deciduous-broadleaved forests, the $T_{\min }$ slopes of grassland patches are $0.011 \pm 0.002,0.003 \pm 0.002$, and $0.016 \pm 0.003{ }^{\circ} \mathrm{C} \mathrm{yr}^{-1}$ for wet year, growing, and nongrowing season, respectively. For those grassland patches with slopes significantly greater than 0 or lower than 0 at $p<0.05$ (one-tail test), the mean slope of $T_{\min }$ during growing season is $0.049 \pm 0.002(\mathrm{n}=34)$ for positive slopes and $-0.08 \pm 0.001(\mathrm{n}=13)^{\circ} \mathrm{C} \mathrm{yr}^{-1}$ for negative slopes. The nongrowing-season $T_{\max }$ also mostly decreased with mean of $-0.016 \pm 0.001{ }^{\circ} \mathrm{C} \mathrm{yr}^{-1}$ (Figure 4c) for the forest patches, however, none of the trends are significant. $T_{\max }$ mostly decreased for the grasslands patches during the growing season with mean slope of $-0.039 \pm 0.003$ for all patches, and $-0.095 \pm 0.001{ }^{\circ} \mathrm{C} \mathrm{yr}^{-1}$ for 61 patches with significant negative slopes (significantly lower than 0 at $p<0.05$ ). However, $T_{\max }$ mostly increased during the nongrowing season with mean of $0.034 \pm 0.002{ }^{\circ} \mathrm{C} \mathrm{yr}^{-1}$. The decreased maximum temperature of the grassland patches in the growing season may be a result of the increasing precipitation.

\subsection{Partial Correlations between EVI and Climate Variables}

$\mathrm{EVI}_{a}$ showed very high partial correlations with both wet-year $(0.57 \pm 0.01)$ and growing-season precipitation $(0.55 \pm 0.02)$ for the grassland patches (Figures 5a and 6). There are 210 and 200 grassland patches exhibiting the positive partial correlations significant at $p<0.05$ (one-tail test) with wet-year $(0.72 \pm 0.01)$ and growing-season precipitation $(0.72 \pm 0.01)$, respectively. For the deciduous-broadleaved forest patches, $\mathrm{EVI}_{a}$ also showed mostly positive partial correlations with wet-year $(0.19 \pm 0.01)$ and nongrowing-season precipitation $(0.21 \pm 0.01)$, especially those patches in the southern part. There are 96 and 94 forest patches having positive partial correlations significant at $p<0.05$ between $\mathrm{EVI}_{a}$ and precipitation in wet year and nongrowing season with coefficients of $0.57 \pm 0.01$ and $0.68 \pm 0.01$, respectively. Maximum EVI $\left(\mathrm{EVI}_{m}\right)$ of the grassland patches also showed positive correlations with both wet-year $(0.39 \pm 0.02)$ and growing-season precipitation $(0.31 \pm 0.02)$ (Figure 6), and 147 and 65 grassland patches showed positive correlation significant at $p<0.05$ (one-tail test) with wet-year and growing-season precipitation at coefficients of $0.65 \pm 0.01$ and $0.64 \pm 0.01$, respectively. The histograms of significant partial correlations detected as greater than 0 or lower than 0 at $p<0.025$ (one-tail test) are shown in Appendix A Figure A2 for reference. 


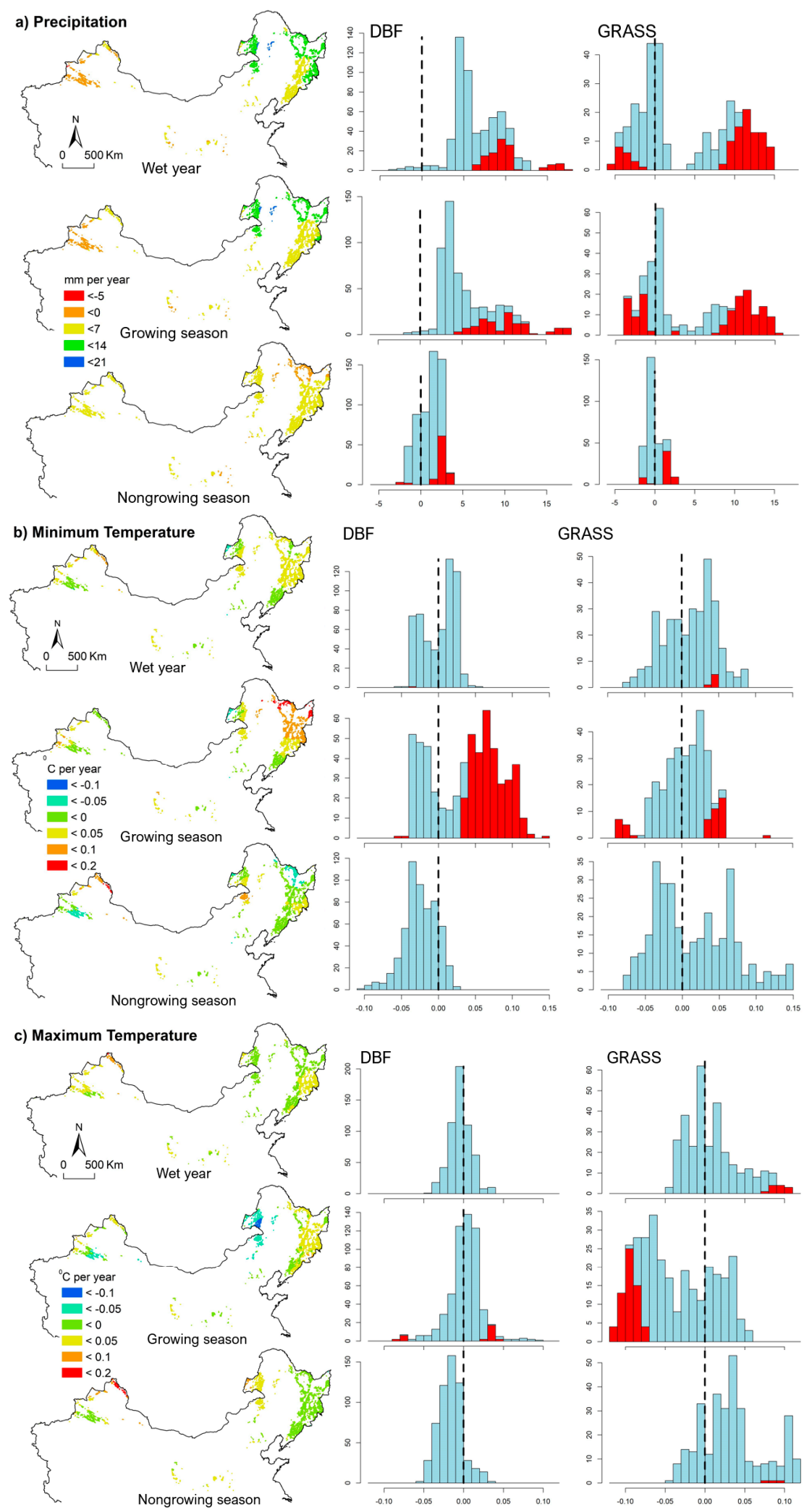

Figure 4. Trends of total precipitation (a), average minimum temperature (b), and average maximum temperature (c) during wet year (prior October to September), growing season (May to September), and nongrowing season (prior October to April) in 2001-2015 for the grassland (GRASS) and deciduous-broadleaved forest (DBF) patches. Right columns are histograms, and red bars on the left side of the dashed line indicate those trends significantly lower than 0 while those on the right side of the dashed line indicate those trends significantly greater than 0 ( $p$-value $<0.05$, one-tail test). 

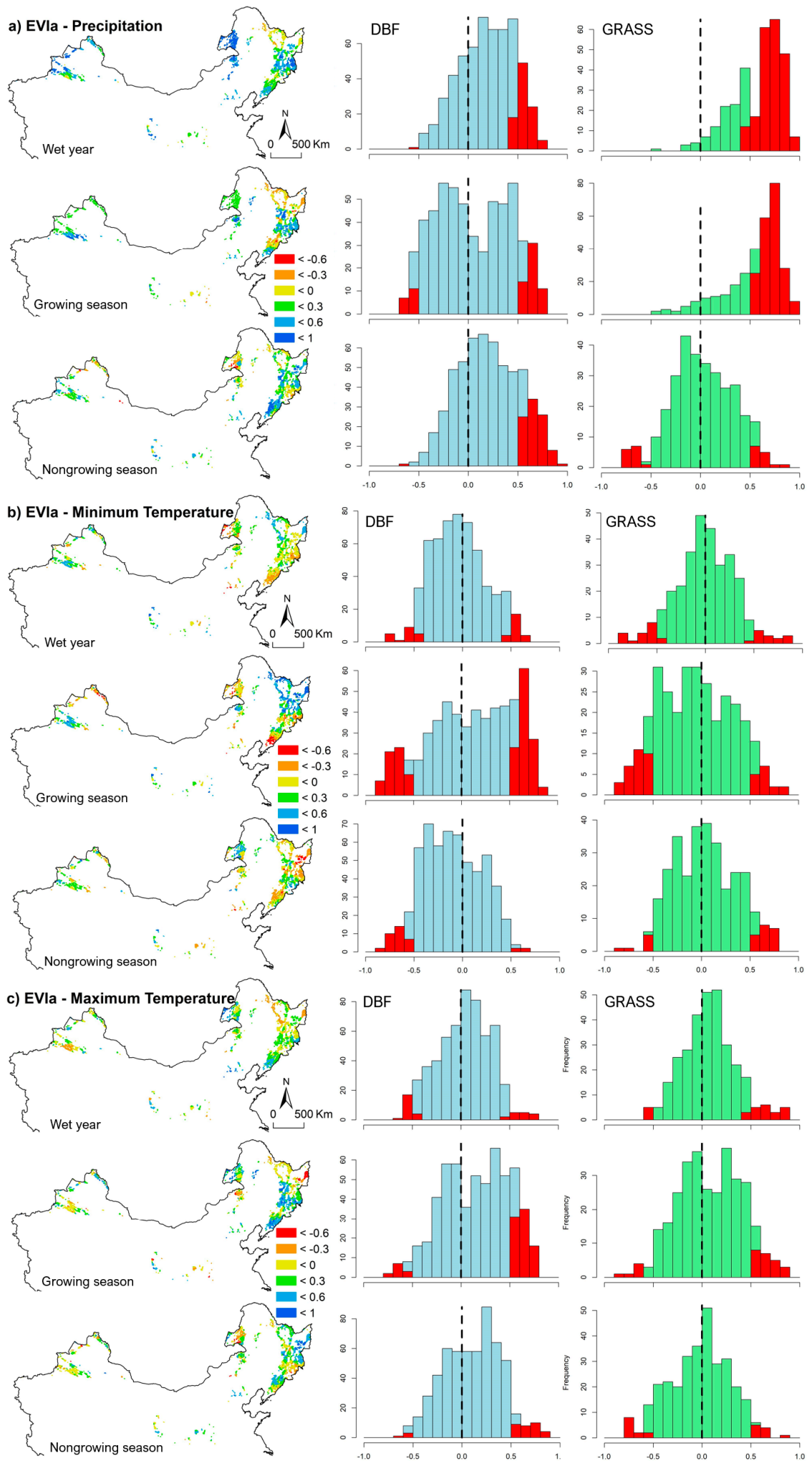

Figure 5. Partial Correlation between $\mathrm{EVI}_{a}$ and climate variables of precipitation (a), minimum temperature (b), and maximum temperature (c) during wet year, growing season, and nongrowing season in 2001-2015 for the grassland (GRASS) and deciduous-broadleaved forest patches (DBF). Right columns are histograms of partial correlation coefficients, and red bars on the left side of the dashed line indicate those partial correlations significantly lower than 0 while those on the right side of the dashed line indicate those partial correlations significantly greater than 0 ( $p$-value $<0.05$, one-tail test). 

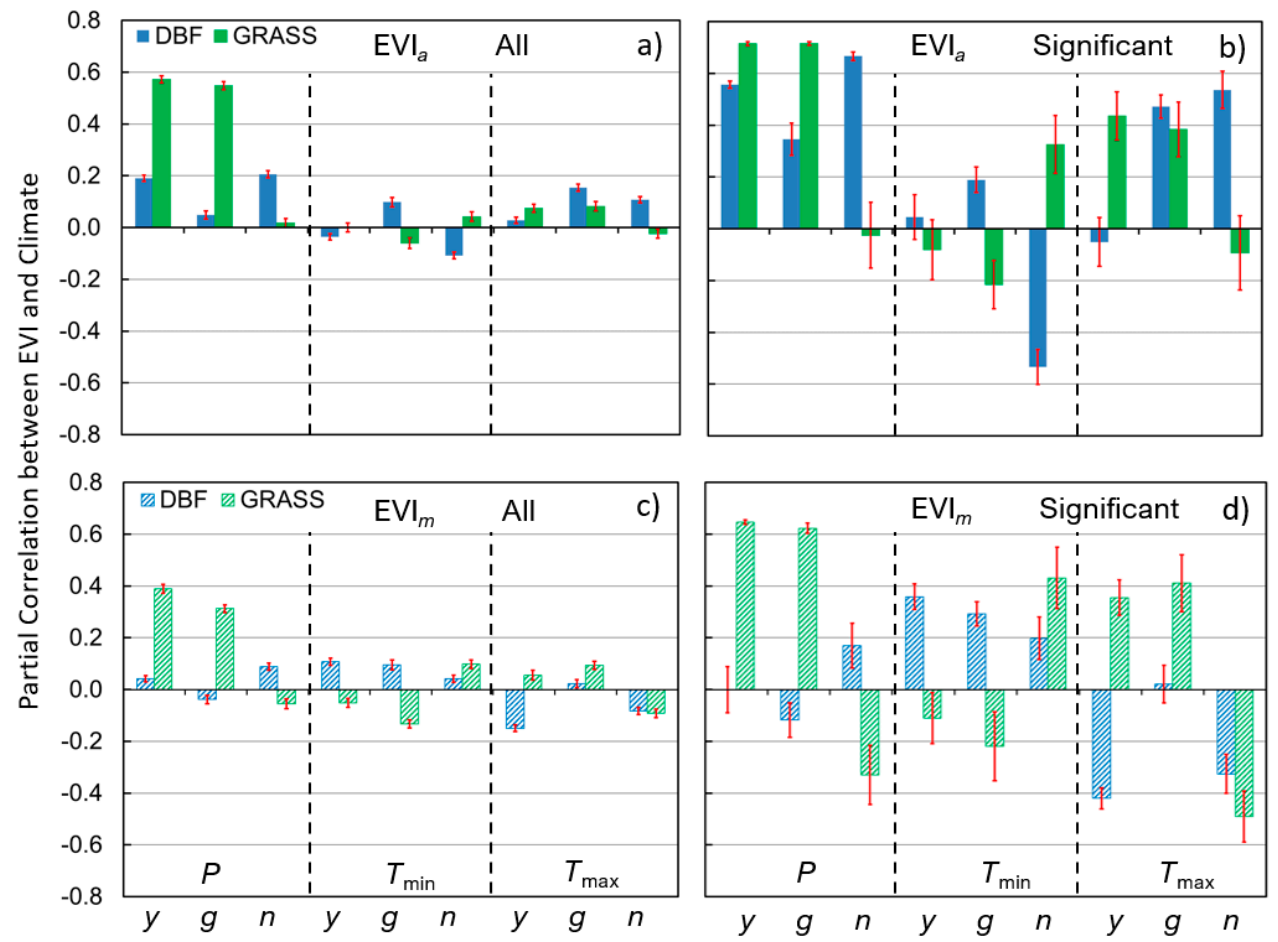

Figure 6. Partial Correlation between EVI and climate variables in 2001-2015 for the grassland (GRASS) and deciduous-broadleaved forest (DBF) patches. $\mathrm{EVI}_{a}$ and $\mathrm{EVI}_{m}$ indicate averaged and maximum EVI during growing season, respectively; $P, T_{\min }, T_{\max }$ indicate precipitation, minimax, and maximum temperatures, respectively; $y, g$, and $n$ indicate wet year, growing season, and nongrowing season, respectively. Panels $(\mathbf{a}, \mathbf{c})$ summarize all partial correlations; panels $(\mathbf{b}, \mathbf{d})$ summarize the significant partial correlations, i.e., significantly lower than 0 or significantly greater than $0(p<0.05$, one-tail test).

The partial correlation between $\mathrm{EVI}_{a}$ and growing-season $T_{\min }$ (Figure $5 \mathrm{~b}$ ) showed distinct spatial heterogeneity among forest patches: 115 patches in the north showed significant positive correlations with coefficient of $0.66 \pm 0.01$ whereas 61 patches in the south showed mostly significant negative correlation with coefficient of $-0.70 \pm 0.01$. There are 33 forest patches showing significant negative partial correlations between $\mathrm{EVI}_{a}$ and nongrowing-season $T_{\min }$ with coefficient of $-0.67 \pm 0.01$. $\mathrm{EVI}_{m}$ of forest patches also showed heterogeneous partial correlation with growing-season $T_{\min }$ : 122 patches have significant positive coefficient of $0.67 \pm 0.01$ and 48 patches have significant negative coefficient of $-0.67 \pm 0.01$. For grassland patches, both $\mathrm{EVI}_{a}$ and $\mathrm{EVI}_{m}$ showed a barely negative partial correlation with growing-season $T_{\min }$ with coefficients of $-0.06 \pm 0.02$ and $-0.13 \pm 0.02$, respectively, but positive correlation with nongrowing-season $T_{\min }$ with coefficients of $0.04 \pm 0.02$ and $0.10 \pm 0.02$, respectively.

The partial correlation between $\mathrm{EVI}_{a}$ and growing-season $T_{\max }$ (Figure $5 \mathrm{c}$ ) also showed spatial heterogeneity among the forest patches, but opposite to that pattern with growing-season $T_{\min }$ (Figure 5b): 82 patches mostly distributed in the south showed significant positive correlations $(0.64 \pm 0.01, p<0.05$, one-tail test), while only 12 patches, mostly in the north, showed significant negative correlations $(-0.65 \pm 0.02)$. There are 31 patches mostly in the north showing significant positive partial correlations between $\mathrm{EVI}_{a}$ and nongrowing-season $T_{\max }(0.68 \pm 0.02)$. $\mathrm{EVI}_{m}$ also showed heterogeneous partial correlation with growing-season $T_{\max }$ with 43 patches mostly in the south showing significant positive coefficients $(0.64 \pm 0.01)$ and 39 patches mostly in the north showing significant negative correlations $(-0.66 \pm 0.01)$. Contrary to the mostly positive correlations between $\mathrm{EVI}_{a}$ and nongrowing-season $T_{\max }$ abovementioned, there are 43 patches mostly in the south showing significant negative partial correlations between $\mathrm{EVI}_{m}$ and nongrowing-season $T_{\max }$ $(-0.65 \pm 0.01)$. For grassland patches, both $\mathrm{EVI}_{a}$ and $\mathrm{EVI}_{m}$ showed a slightly positive partial correlation with growing-season $T_{\max }$ with coefficients of $0.08 \pm 0.02$ and $0.09 \pm 0.02$, respectively, whereas a barely 
negative correlation was found with nongrowing-season $T_{\max }$ with coefficients of $-0.02 \pm 0.02$ and $-0.09 \pm 0.02$, respectively.

\section{Discussion}

Although greening in China and India has been highlighted recently and mostly attributed to the land-use management such as reforestation and afforestation efforts and multiple cropping albeit in the process of urbanization [6,41], it is largely unknown how climate alone has contributed to the greening. Our approach in this study allowed us to obtain a 'cleaner' and unbiased relationship between vegetation greenness and climate change by insulating from the impact of land-cover changes.

The greenness of temperate grasslands is primarily precipitation-controlled compared to that of temperate deciduous forests co-controlled by temperature and precipitation [42,43]. Precipitation, especially in growing season, dominates the greenness dynamics in the temperate grasslands in Northern China (Figure 5). Compared to trees in the forests, grass has shallow-root system which limits its uptake of water/nutrients from deep soil layers. Therefore, green biomass production of temperate grasslands fluctuates with rainfall, especially the growing-season rainfall. The analyses on the gross primary productivity (GPP) over China indicated that the GPP in the temperate semi-arid grasslands is dominated by precipitation [44,45]. In the US Great Basin, the interannual variation of vegetation greenness was found to strongly correlated with total precipitation, but not surface air temperature [46].

The diurnal and seasonal dynamics of temperature interacts with wet-year precipitation especially that in nongrowing seasons to coregulate greenness of temperate deciduous-broadleaved forests (Figure 5). In addition to the well-developed root systems that hold the moisture from both shallow and deep soil horizons, trees have much more functional biomass than grasses to maintain and higher longevity than grasses which makes trees sensitive to intra- and inter-annual climate variability and phenology changes $[7,14]$. Our results showed that wet-year especially nongrowing-season precipitation contributes to the greenness of deciduous-broadleaved forests (Figure 5), whereas grassland greenness is strongly correlated to growing-season precipitation. More importantly, daytime (maximum) and nighttime (minimum) temperatures have asymmetric effects on the production and leaf growth of trees in deciduous-broadleaved forests, and the asymmetric effects are highly spatially heterogeneous (Figure 5). Nighttime warming as reflected in increased minimum temperature in general elevates respiration cost, thus tends to reduce leaf growth. On the other hand, nighttime warming tends to reduce the chances of frost damage so that to extend the growing season in early spring and autumn, hence favors the seasonal peak and average greenness $[19,20]$. In the temperature-limited northern part of the deciduous-broadleaved forests, the net effect of nighttime warming tends to enhance the greenness (Figure 5b) due to the benefit from lengthening growing season [14]. However, in the warmer southern part, the higher maintenance cost contributes to a negative net effect of nighttime warming (Figure 5b) which reduces leaf growth and greenness.

Daytime temperature directly regulates photosynthetic enzyme activities during growing season, but also causes water loss through evapotranspiration which can exert drought stress on photosynthesis. The contrasting pattern of the greenness responses to daytime temperature $\left(T_{\max }\right.$, Figure $\left.5 \mathrm{c}\right)$ between the northern and the southern deciduous-broadleaved forests could be attributed to species composition with birch and poplar dominated in the north while oak dominated in the south. Oak is more drought-tolerant than birch or poplar [12], and thus is less sensitive to drought condition during the growing season. Therefore, the oak-dominated southern part exhibited positive net effect of $T_{\text {max }}$ on greenness due to enhanced photosynthetic activities. The studies on fall phenology in New England [13] also found that the maple and birch dominated northeastern highlands had higher sensitivity to drought than the corresponding southern coastal zone dominated by oak.

Phenology changes in response to climate might also contribute indirectly to our observed pattern in vegetation greenness. For example, cooling winter helps trees to meet chilling requirements to break dormancy and the cooling winter but warming early spring is found to advance the growing season 
of deciduous-broadleaved forests in Northern China during 2001-2013 [14]. The onset of green-up advanced on average -2.4 to -0.45 days $\mathrm{yr}^{-1}$ for the deciduous forests with significant changes in the start of growing season during 2001-2013, mostly distributed north of $48^{\circ} \mathrm{N}$ in Northern China [14]. In this study, we also found that both $T_{\max }$ and $T_{\min }$ showed a decreasing trend in nongrowing season in the deciduous forests which might help to advance the green-up (Figure 3). The lengthened growing season, in turn, might help partially explain the significant negative correlation between EVI and nongrowing season $T_{\min }$ that we found in the north (Figure $5 \mathrm{~b}$ ), that is, cooling winter relates to advanced green-up and the lengthened growing season favors high greenness.

The Earth System Modeling predicted that the high-latitude northern regions will continue the greening trend till 2100, which will enhance the regional C sequestration, strengthen regional hydrological dynamics, and induce localized warming via reduced albedo or cooling via transpiration [47]. This study made efforts to disentangle the climate contribution to greenness of temperate vegetations from land-use contribution which is essential in mechanistic understanding of the interactions of multiple drivers. These efforts are also important for our knowledge about greening, rational land-use planning, and natural-resource management for climate change mitigation. Our current study focuses on the vegetation greenness in response to climate without considering the changes in atmospheric $\mathrm{CO}_{2}$ concentration or nitrogen deposition that also drive greenness [2]. Further advancement in remote sensing will likely provide the atmospheric $\mathrm{CO}_{2}$ concentration and nitrogen deposition datasets with the spatial and temporal resolutions compatible to those in greenness or climate, thus leads to more comprehensive understanding of the drivers of vegetation greenness. In this study, we used the deciduous-broadleaved forest as an example to interpret that the differentiated relationship between greenness and climate might be attributed to the species composition. Further studies to link species composition to grassland greenness in response to climate based on ecophysiology will help elucidate this mechanism in various ecosystems.

\section{Conclusions}

Temperate grassland and deciduous forests in Northern China are in general experiencing wetting in recent decades and the vegetations are greening amongst major land-cover/use changes such as afforestation and reforestation. Our analyses on the greenness dynamics of large grassland and forest patches without land-cover/use changes addressed the direct climate contribution on greenness, separated from those of land-cover/use changes. Although both are in general greening, temperate deciduous forest and grassland have different mechanisms in their responses to climate changes. Compared to the well-developed root systems of forests, the shallow-root grasslands are more sensitive to precipitation and the greening is mostly supported by enhanced summer rainfall. While precipitation especially that in nongrowing season favors the forest greenness, it is also highly regulated by asymmetric warming diurnally and seasonally, and the spatially differentiated greenness response to climate could be attributed to species composition.

Author Contributions: Conceptualization, M.Y. and Q.G.; methodology, M.Y.; formal analysis, M.Y. and Q.G.; writing, M.Y. and Q.G. All authors have read and agreed to the published version of the manuscript.

Funding: This research received no external funding.

Acknowledgments: We acknowledge the following data providers. The climate data supporting this analysis are based on publicly available datasets from China Meteorological Service (https://data.cma.cn/en). The vegetation index and land cover are based on publicly available datasets from USGS (https://lpdaac.usgs.gov/) and Google Earth Engine (https://developers.google.com/earth-engine/datasets/catalog/modis).

Conflicts of Interest: The authors declare no conflict of interest. 


\section{Appendix A}

(a)
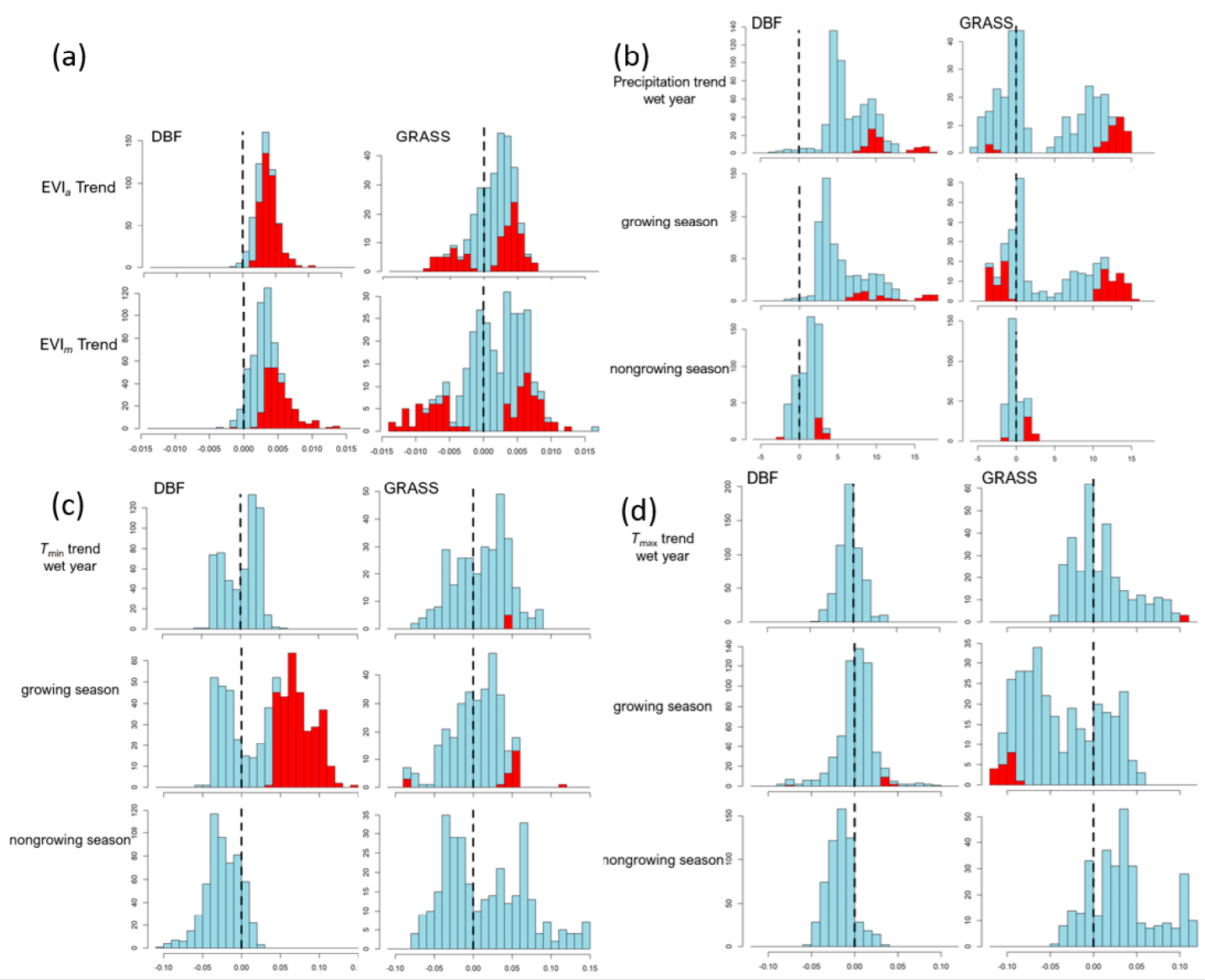

Figure A1. Histograms of trends of averaged and maximum EVI $\left(\mathrm{yr}^{-1}\right)$ (a) during growing season, May-September, and of total precipitation (b), average minimum temperature $T_{\min }(\mathbf{c})$, and average maximum temperature $T_{\max }$ (d) during wet year (prior October to September), growing season (May to September), and nongrowing season (prior October to April) in 2001-2015 for the grassland (GRASS) and deciduous-broadleaved forest (DBF) patches. $\mathrm{EVI}_{a}$ and $\mathrm{EVI}_{m}$ indicate averaged and maximum EVI during growing season, respectively. Red bars on the left side of the dashed line indicate those trends significantly lower than 0 while those on the right side of the dashed line indicate the trends significantly greater than 0 ( $p$-value $<0.025$, one-tail test). 


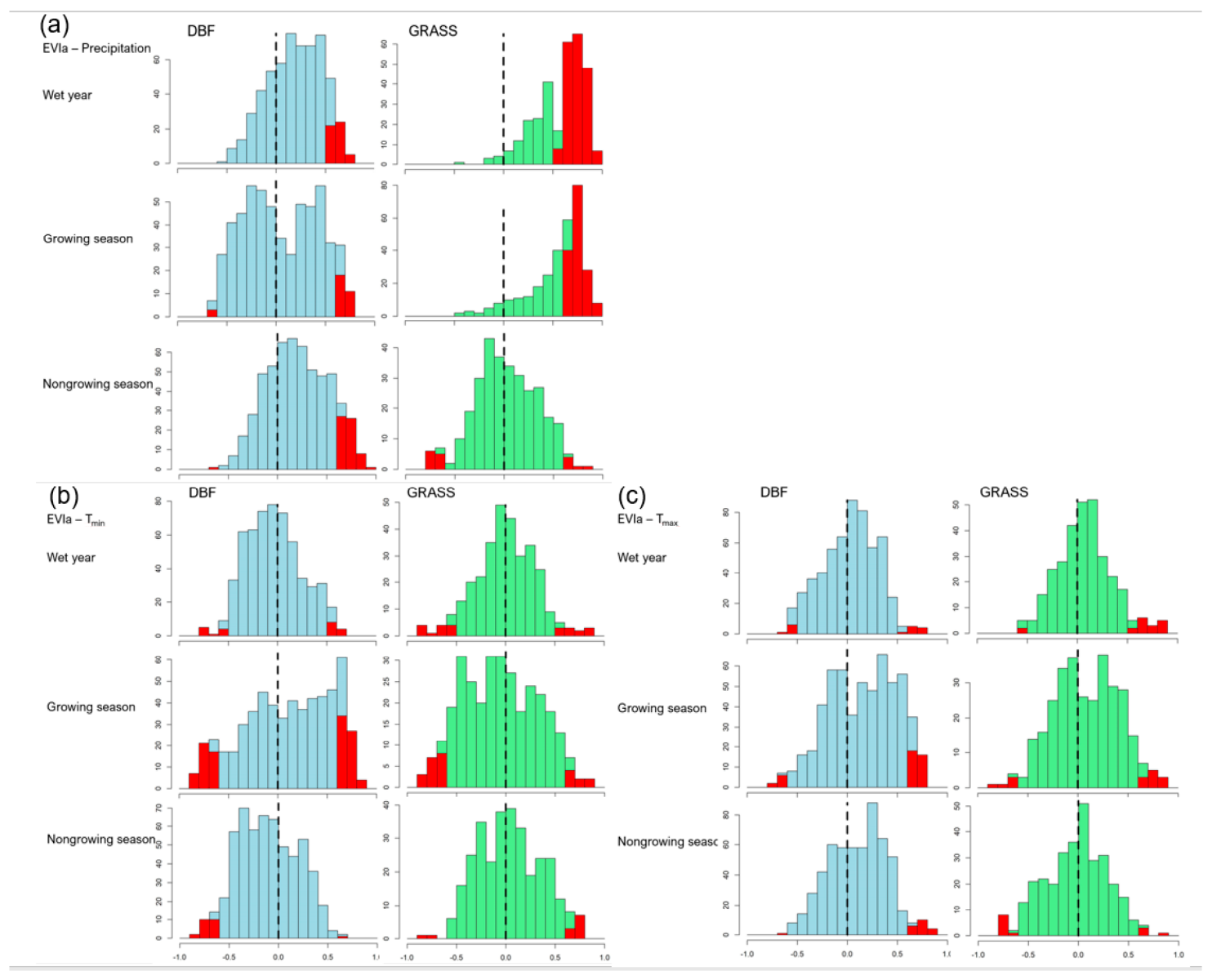

Figure A2. Histograms of Partial Correlation between $\mathrm{EVI}_{a}$ and climate variables of Precipitation (a), Minimum Temperature $T_{\min }(\mathbf{b})$, and Maximum Temperature $T_{\max }(\mathbf{c})$ during wet year, growing season, and nongrowing season in 2001-2015 for the grassland (GRASS) and deciduous-broadleaved forest patches (DBF). Red bars on the left side of the dashed line indicate those partial correlations significantly lower than 0 while those on the right side of the dashed line indicate those partial correlations significantly greater than 0 ( $p$-value $<0.025$, one-tail test).

\section{References}

1. Huete, A.; Didan, K.; Miura, T.; Rodriguez, E.P.; Gao, X.; Ferreira, L.G. Overview of the radiometric and biophysical performance of the MODIS vegetation indices. Remote Sens. Environ. 2002, 83, 195-213. [CrossRef]

2. Piao, S.; Wang, X.; Park, T.; Chen, C.; Lian, X.; He, Y.; Bjerke, J.W.; Chen, A.; Ciais, P.; Tømmervik, H.; et al. Characteristics, drivers and feedbacks of global greening. Nat. Rev. Earth Environ. 2020, 1, 14-27. [CrossRef]

3. Griffiths, P.; Nendel, C.; Hostert, P. Intra-annual reflectance composites from Sentinel-2 and Landsat for national-scale crop and land cover mapping. Remote Sens. Environ. 2019, 220, 135-151. [CrossRef]

4. Zhang, X.; Liu, L.; Henebry, G.M. Impacts of land cover and land use change on long-term trend of land surface phenology: A case study in agricultural ecosystems. Environ. Res. Lett. 2019, 14, 044020. [CrossRef]

5. Ganguly, S.; Friedl, M.A.; Tan, B.; Zhang, X.Y.; Verma, M. Land surface phenology from MODIS: Characterization of the Collection 5 global land cover dynamics product. Remote Sens. Environ. 2010, 114, 1805-1816. [CrossRef]

6. Chen, C.; Park, T.; Wang, X.; Piao, S.; Xu, B.; Chaturvedi, R.K.; Fuchs, R.; Brovkin, V.; Ciais, P.; Fensholt, R.; et al. China and India lead in greening of the world through land-use management. Nat. Sustain. 2019, 2, 122-129. [CrossRef] [PubMed] 
7. Gao, Q.; Yu, M.; Xu, H. Directional Climate Trend, Intensified Intraannual Variability, and Changes in Land Cover Drive the Dynamics of Vegetation Greenness in Peri-Urban China During 2001-2015. J. Geophys. Res. Biogeosci. 2020, 125, e2019JG005336. [CrossRef]

8. Chapin, F.S.; Matson, P.A.; Vitousek, P.M. Principles of Terrestrial Ecosystem Ecology, 2nd ed.; Springer: New York, NY, USA, 2012; p. 529.

9. Yu, M.; Gao, Q.; Liu, Y.H.; Xu, H.M.; Shi, P.J. Responses of vegetation structure and primary production of a forest transect in eastern China to global change. Glob. Ecol. Biogeogr. 2002, 11, 223-236. [CrossRef]

10. Yu, M.; Gao, Q.; Guo, J.P. Sensitivity analysis of individual responses of plants to global change. J. Integr. Plant Biol. 1998, 40, 1143-1151.

11. Gao, Q.; Yu, M. A model of regional vegetation dynamics and its application to the study of Northeast China Transect (NECT) responses to global change. Glob. Biogeochem. Cycles 1998, 12, 329-344. [CrossRef]

12. Yu, M.; Gao, Q. Leaf-traits and growth allometry explain competition and differences in response to climatic change in a temperate forest landscape: A simulation study. Ann. Bot. 2011, 108, 885-894. [CrossRef] [PubMed]

13. Xie, Y.; Wang, X.; Silander, J.A. Deciduous forest responses to temperature, precipitation, and drought imply complex climate change impacts. Proc. Natl. Acad. Sci. USA 2015, 112, 13585-13590. [CrossRef] [PubMed]

14. Wang, X.; Gao, Q.; Wang, C.; Yu, M. Spatiotemporal patterns of vegetation phenology change and relationships with climate in the two transects of East China. Glob. Ecol. Conserv. 2017, 10, 206-219. [CrossRef]

15. Fu, Y.H.; Piao, S.; Op de Beeck, M.; Cong, N.; Zhao, H.; Zhang, Y.; Menzel, A.; Janssens, I.A. Recent spring phenology shifts in western Central Europe based on multiscale observations. Glob. Ecol. Biogeogr. 2014, 23, 1255-1263. [CrossRef]

16. Gao, Q.; Yu, M.; Liu, Y.; Xu, H.; Xu, X. Modeling interplay between regional net ecosystem carbon balance and soil erosion for a crop-pasture region. J. Geophys. Res.-Biogeosci. 2007, 112. [CrossRef]

17. Richardson, A.D.; Hufkens, K.; Milliman, T.; Aubrecht, D.M.; Furze, M.E.; Seyednasrollah, B.; Krassovski, M.B.; Latimer, J.M.; Nettles, W.R.; Heiderman, R.R.; et al. Ecosystem warming extends vegetation activity but heightens vulnerability to cold temperatures. Nature 2018, 560, 368-371. [CrossRef]

18. Mo, X.G.; Liu, S.X. Simulating evapotranspiration and photosynthesis of winter wheat over the growing season. Agric. For. Meteorol. 2001, 109, 203-222. [CrossRef]

19. Peng, S.; Piao, S.; Ciais, P.; Myneni, R.B.; Chen, A.; Chevallier, F.; Dolman, A.J.; Janssens, I.A.; Penuelas, J.; Zhang, G.; et al. Asymmetric effects of daytime and night-time warming on Northern Hemisphere vegetation. Nature 2013, 501, 88-92. [CrossRef]

20. Anderegg, W.R.L.; Ballantyne, A.P.; Smith, W.K.; Majkut, J.; Rabin, S.; Beaulieu, C.; Birdsey, R.; Dunne, J.P.; Houghton, R.A.; Myneni, R.B.; et al. Tropical nighttime warming as a dominant driver of variability in the terrestrial carbon sink. Proc. Natl. Acad. Sci. USA 2015, 112, 15591-15596. [CrossRef]

21. Yu, M.; Gao, Q.; Gao, C.; Wang, C. Extent of Night Warming and Spatially Heterogeneous Cloudiness Differentiate Temporal Trend of Greenness in Mountainous Tropics in the New Century. Sci. Rep. 2017, 7, 41256. [CrossRef]

22. IPCC. Climate Change 2013: The Physical Science Basis. Contribution of Working Group I to the Fifth Assessment Report of the Intergovernmental Panel on Climate Change; Stocker, T.F., Qin, D., Plattner, G.-K., Tignor, M., Allen, S.K., Boschung, J., Nauels, A., Xia, Y., Bex, V., Midgley, P.M., Eds.; Cambridge University Press: Cambridge, UK; New York, NY, USA, 2013; p. 1535. [CrossRef]

23. Shen, M.; Piao, S.; Chen, X.; An, S.; Fu, Y.H.; Wang, S.; Cong, N.; Janssens, I.A. Strong impacts of daily minimum temperature on the green-up date and summer greenness of the Tibetan Plateau. Glob. Chang. Biol. 2016, 22, 3057-3066. [CrossRef]

24. Polgar, C.; Gallinat, A.; Primack, R.B. Drivers of leaf-out phenology and their implications for species invasions: Insights from Thoreau's Concord. New Phytol. 2014, 202, 106-115. [CrossRef]

25. Polgar, C.A.; Primack, R.B. Leaf-out phenology of temperate woody plants: From trees to ecosystems. New Phytol. 2011, 191, 926-941. [CrossRef]

26. Dieguez, H.; Paruelo, J.M. Disentangling the signal of climatic fluctuations from land use: Changes in ecosystem functioning in South American protected areas (1982-2012). Remote Sens. Ecol. Conserv. 2017, 3, 177-189. [CrossRef]

27. Gao, Q.; Yu, M.; Zhang, X.S.; Xu, H.M.; Huang, Y.M. Modelling seasonal and diurnal dynamics of stomatal conductance of plants in a semiarid environment. Funct. Plant Biol. 2005, 32, 583-598. [CrossRef] 
28. Yu, M.; Xie, Y.; Zhang, X. Quantification of Intrinsic Water Use Efficiency along a Moisture Gradient in Northeastern China. J. Environ. Qual. 2005, 34, 1311-1318. [CrossRef]

29. Zhang, X.D.; He, J.X.; Zhang, J.; Polyakov, I.; Gerdes, R.; Inoue, J.; Wu, P.L. Enhanced poleward moisture transport and amplified northern high-latitude wetting trend. Nat. Clim. Chang. 2013, 3, 47-51. [CrossRef]

30. Yu, M.; Gao, Q.; Epstein, H.E. Ecophysiological characteristics on photosynthesis and stomatal conductance of dominant C3 and C4 species in semi-arid and arid grassland. S. Afr. J. Bot. 2009, 75, 518-525. [CrossRef]

31. Turnbull, M.H.; Murthy, R.; Griffin, K.L. The relative impacts of daytime and night-time warming on photosynthetic capacity in Populus deltoides. Plant Cell Environ. 2002, 25, 1729-1737. [CrossRef]

32. Wan, S.; Xia, J.; Liu, W.; Niu, S. Photosynthetic overcompensation under nocturnal warming enhances grassland carbon sequestration. Ecology 2009, 90, 2700-2710. [CrossRef]

33. Peters, D.P.C.; Yao, J.; Browning, D.; Rango, A. Mechanisms of grass response in grasslands and shrublands during dry or wet periods. Oecologia 2014, 174, 1323-1334. [CrossRef] [PubMed]

34. Wang, C.; Gao, Q.; Wang, X.; Yu, M. Decadal Trend in Agricultural Abandonment and Woodland Expansion in an Agro-Pastoral Transition Band in Northern China. PLoS ONE 2015, 10, e0142113. [CrossRef]

35. Wang, C.; Gao, Q.; Yu, M. Quantifying Trends of Land Change in Qinghai-Tibet Plateau during 2001-2015. Remote Sens. 2019, 11, 2435. [CrossRef]

36. Wang, C.; Gao, Q.; Wang, X.; Yu, M. Spatially differentiated trends in urbanization, agricultural land abandonment and reclamation, and woodland recovery in Northern China. Sci. Rep. 2016, 6, 37658. [CrossRef] [PubMed]

37. Didan, K. MOD13Q1 MODIS/Terra Vegetation Indices 16-Day L3 Global 250m SIN Grid V006 [Data set]. Distributed by NASA EOSDIS Land Processes DAAC. Available online: https://doi.org/10.5067/MODIS/ MOD13Q1.006 (accessed on 8 August 2020).

38. Gorelick, N.; Hancher, M.; Dixon, M.; Ilyushchenko, S.; Thau, D.; Moore, R. Google Earth Engine: Planetary-scale geospatial analysis for everyone. Remote Sens. Environ. 2017, 202, 18-27. [CrossRef]

39. Pinheiro, J.; Bates, D.; DebRoy, S.; Sarkar, D.; R Core Team. nlme: Linear and Nonlinear Mixed Effects Models, 2020; R package 3.1-147. Available online: https:/CRAN.R-project.org/package=nlme (accessed on 8 August 2020).

40. Kim, S. ppcor: An R Package for a Fast Calculation to Semi-partial Correlation Coefficients. Commun. Statist. Appl. Methods 2015, 22, 665-674. [CrossRef]

41. Zhang, Y.; Song, C.; Band, L.E.; Sun, G.; Li, J. Reanalysis of global terrestrial vegetation trends from MODIS products: Browning or greening? Remote Sens. Environ. 2017, 191, 145-155. [CrossRef]

42. Nemani, R.R.; Keeling, C.D.; Hashimoto, H.; Jolly, W.M.; Piper, S.C.; Tucker, C.J.; Myneni, R.B.; Running, S.W. Climate-driven increases in global terrestrial net primary production from 1982 to 1999. Science 2003, 300, 1560-1563. [CrossRef]

43. Seddon, A.W.R.; Macias-Fauria, M.; Long, P.R.; Benz, D.; Willis, K.J. Sensitivity of global terrestrial ecosystems to climate variability. Nature 2016, 531, 229-232. [CrossRef]

44. Yao, Y.T.; Wang, X.H.; Li, Y.; Wang, T.; Shen, M.G.; Du, M.Y.; He, H.L.; Li, Y.N.; Luo, W.J.; Ma, M.G.; et al. Spatiotemporal pattern of gross primary productivity and its covariation with climate in China over the last thirty years. Glob. Chang. Biol. 2018, 24, 184-196. [CrossRef]

45. Yu, M.; Ellis, J.E.; Epstein, H.E. Regional analysis of climate, primary production, and livestock density in Inner Mongolia. J. Environ. Qual. 2004, 33, 1675-1681. [CrossRef] [PubMed]

46. Tang, G.; Arnone Iii, J.A.; Verburg, P.; Jasoni, R.L. Trend and climatic sensitivity of vegetation phenology in semiarid and arid ecosystems in the US Great Basin during 1982-2011. Biogeosci. Discuss. 2015, 12, 11387-11422. [CrossRef]

47. Mahowald, N.; Lo, F.; Zheng, Y.; Harrison, L.; Funk, C.; Lombardozzi, D.; Goodale, C. Projections of leaf area index in earth system models. Earth Syst. Dyn. 2016, 7, 211-229. [CrossRef]

(C) 2020 by the authors. Licensee MDPI, Basel, Switzerland. This article is an open access article distributed under the terms and conditions of the Creative Commons Attribution (CC BY) license (http://creativecommons.org/licenses/by/4.0/). 